\title{
A randomized double-blind trial comparing the effect on pain of an oral sucrose solution versus placebo in children 1-3 months old needing bladder catheterization
}

\author{
Marie Pier Desjardins ${ }^{1}$ (]) $\cdot$ Nathalie Gaucher ${ }^{1} \cdot$ Jocelyn Gravel $^{1} \cdot$ Denis Lebel ${ }^{2} \cdot$ Serge Gouin $^{1}$
}

Received: 30 December 2020 / Accepted: 29 March 2021 / Published online: 26 May 2021

(c) The Author(s), under exclusive licence to Canadian Association of Emergency Physicians (CAEP)/ Association Canadienne de Médecine d'Urgence (ACMU) 2021

\begin{abstract}
Objective The efficacy of oral sweet solutions to decrease pain in infants during painful procedures remains uncertain. This study aimed to compare the efficacy of an oral sucrose solution versus placebo in reducing pain during bladder catheterization in infants in the Emergency Department (ED).

Methods A randomized, double-blind clinical trial was conducted in a pediatric university-affiliated hospital ED. Infants 1-3 months old were recruited and randomly allocated to receive $2 \mathrm{ml}$ of sucrose or placebo, $2 \mathrm{~min}$ before bladder catheterization. The primary outcome measure was the difference in pain scores as assessed by the Face, Legs, Activity, Cry and Consolability (FLACC) Pain Scale during procedure. Secondary outcome measures were the difference in pain scores using the Neonatal Infant Pain Scale (NIPS), crying time, variations in heart rate and adverse events.

Results Eighty-three participants were recruited and completed the study, 41 and 42 in the sucrose and placebo groups, respectively. The mean difference in FLACC scores compared to baseline was 5.3 in the sucrose group vs. 6.4 in the placebo group during catheterization. There were no differences in FLACC scores or NIPS scores measured at 1, 3 and 5 min post procedure. Mean crying times were similar: 97 vs. 110 s. No significant difference was found in participants' heart rate variations. No adverse events were reported.

Conclusions In infants undergoing bladder catheterization in the ED, administration of an oral sweet solution was not associated with lower pain as measured by the FLACC and NIPS scales. Participants' heart rate variations and crying times did not change when sucrose was provided.
\end{abstract}

Keywords Infant $\cdot$ Pediatric emergency medicine $\cdot$ Pain $\cdot$ Sucrose $\cdot$ Bladder catheterization

\section{Résumé}

Objectif L'efficacité des solutions sucrées orales pour diminuer la douleur chez les nourrissons pendant les procédures douloureuses reste incertaine. Cette étude visait à comparer l'efficacité d'une solution de saccharose orale par rapport à un placebo pour réduire la douleur pendant le cathétérisme vésical chez les nourrissons dans le service d'urgence.

Méthodes Un essai clinique randomisé en double aveugle a été mené dans les urgences d'un hôpital universitaire pédiatrique. Des nourrissons âgés de 1 à 3 mois ont été recrutés et répartis au hasard pour recevoir $2 \mathrm{ml}$ de sucrose ou de placebo, 2 minutes avant le cathétérisme vésical. La principale mesure des résultats était la différence dans les scores de douleur évalués par l'échelle de douleur FLACC (Face, Legs, Activity, Cry and Consolability) pendant la procédure. Les mesures

Marie Pier Desjardins

mpdesj@gmail.com

1 Department of Pediatrics Emergency, Centre Hospitalier Universitaire Sainte-Justine, Université de Montréal, 3175 Côte-Sainte-Catherine, Montreal, QC H3T 1C5, Canada

2 Department of Pharmacy, Centre Hospitalier Universitaire Sainte-Justine, Université de Montréal, Montreal, QC, Canada 
de résultats secondaires étaient la différence des scores de douleur en utilisant l'échelle de douleur du nourrisson néonatal (NIPS), la durée des pleurs, les variations de la fréquence cardiaque et les événements indésirables.

Résultats Quatre-vingt-trois participants ont été recrutés et ont terminé l'étude, 41 et 42 dans les groupes sucrose et placebo, respectivement. La différence moyenne des scores FLACC par rapport à la ligne de base était de 5,3 dans le groupe sucrose contre 6,4 dans le groupe placebo pendant le cathétérisme. Il n'y avait aucune différence dans les scores FLACC ou NIPS mesurés à 1,3 et 5 minutes après la procédure. La durée moyenne des pleurs était similaire : 97 contre 110 secondes. Aucune différence significative n'a été constatée dans les variations de la fréquence cardiaque des participants. Aucun événement indésirable n'a été signalé.

Conclusions Chez les nourrissons soumis à un cathétérisme vésical aux urgences, l'administration d'une solution sucrée orale n'était pas associée à une douleur moindre, telle que mesurée par les échelles FLACC et NIPS. Les variations de la fréquence cardiaque et les temps de pleurs des participants ne changeaient pas lorsque du saccharose était administré.

\section{Clinician's capsule}

\section{What is known about the topic?}

Painful procedures are frequently performed in children in emergency departments and efforts should seek to minimize procedural pain.

\section{What did the study ask?}

Whether an oral sweet solution administered before bladder catheterization was effective in decreasing pain in infants 1 to 3 months old.

\section{What did this study find?}

Administration of an oral sweet solution before bladder catheterization was not associated with lower pain scores.

\section{Why does this study matter to clinicians?}

Sweet solutions may not provide the desired analgesia during painful procedures; future studies should investigate is potential among this population.

\section{Introduction}

Painful experiences during infancy have a negative impact on children, causing the development of negative neurologic pathways that influence future painful experiences [1]. Procedural pain and anxiety relief are considered essential elements of quality emergency department (ED) care [2]. New noninvasive bladder stimulation techniques have been developed and studied to obtain clean catch urine samples in infants, demonstrating an overall success rate of $49 \%$ (i.e., the collection of $2 \mathrm{ml}$ of urine in less than $5 \mathrm{~min}$ ), a median time to collect urine of $45 \mathrm{~s}$ and a contamination rate of urine culture of $16 \%$ [3]. Given that noninvasive techniques are not successful in half of patients, bladder catheterization is often required to diagnose urinary tract infections in febrile infants $[4,5]$. Bladder catheterization has been demonstrated as a painful procedure and, as of yet, no methods have proven safe and efficacious in decreasing pain sensation during this procedure in children 1-3 months of age [6].
Several studies have demonstrated that administering oral sweet solutions during painful procedures should be the standard of care in infants of less than 1 month of age [7]. Also, studies suggest that sucrose should be administered to treat vaccine associated procedural pain in infants up to the age of 12 months [8-10]. However, data supporting the use of oral sweet solutions to decrease procedural pain in older children have shown conflicting results [11-15]. In a study by Curtis and al, sucrose demonstrated no effect on FLACC scores, crying time and heart rate in infants aged 0 to 6 months requiring venipuncture. However, in sub-group analyses, sucrose trended towards improvements in these outcomes in children aged 0-1 month and 1-3 months, without achieving statistical significance [11]. We therefore sought to investigate the efficacy of sucrose in the subgroup of children aged 1-3 months of age who trended towards statistical significance. Our research team previously found that sucrose did not decrease FLACC scores in infants 1-3 months old during venipuncture, but did have a significant effect on crying time [12]. In a study by Rogers et al. sucrose did not achieve significant analgesia in infants less than 90 days undergoing bladder catheterization in the ED [13]. Similarly, London et al. studied the effect of an oral sucrose solution in children 3 months to 3 years old who underwent bladder catheterization and found a trend in in reducing pain in the sucrose group without achieving statistical significance [14]. Although little is known regarding the long-term neurodevelopmental effects of sucrose in infants, most authors agree that sweet solutions display an overall safe profile and this is even more likely in the context of sporadic interventions, such as those conducted in the ED [16]. Given that sucrose is efficacious in infants less than 1 month old, that studies have demonstrated controversial results in the 1-3 month age group in subgroup analyses and that no study has been conducted specifically in this age group, we sought to study the effect of an oral sucrose solution in infants $1-3$ months old $[7,11,13]$.

The aim of the present study was to evaluate whether the use of an oral sweet solution before bladder catheterization 
was effective in decreasing pain according to the Face, Legs, Activity, Cry and Consolability Pain scale (FLACC) among infants 1-3 months old.

\section{Methods}

\section{Study design and time period}

We conducted a randomized double blinded placebo-controlled study between October 2012 and December 2014. The study was approved by the hospital's institutional Ethics and Review Board and registered with ClinicalTrials.gov (NCT01544985).

\section{Study setting}

The study took place in the ED of a university affiliated pediatric tertiary care center with an annual census of 85,000 visits a year.

\section{Population}

A convenience sample of patients was recruited when a research assistant was available, mainly during weekdays from 8 AM until 6 PM. Patients were eligible if a bladder catheterization was prescribed by the treating emergency physician. All patients 1-3 months old requiring a bladder catheterization as part of their investigation were included. Patient were excluded if they were born before 37 weeks gestational age, had known urinary tract or oropharyngeal malformations, metabolic or chronic cardio-pulmonary conditions, assisted ventilation or technology dependence, acute and severe respiratory illness, and if they had been previously included in the study or had undergone another painful procedure in the 60 min preceding recruitment. We also excluded from the analysis, children who did not have a bladder catheterization (children who micturated while being disinfected and thus provided a "clean catch" urine sample) (Fig. 1).

\section{Study flow}

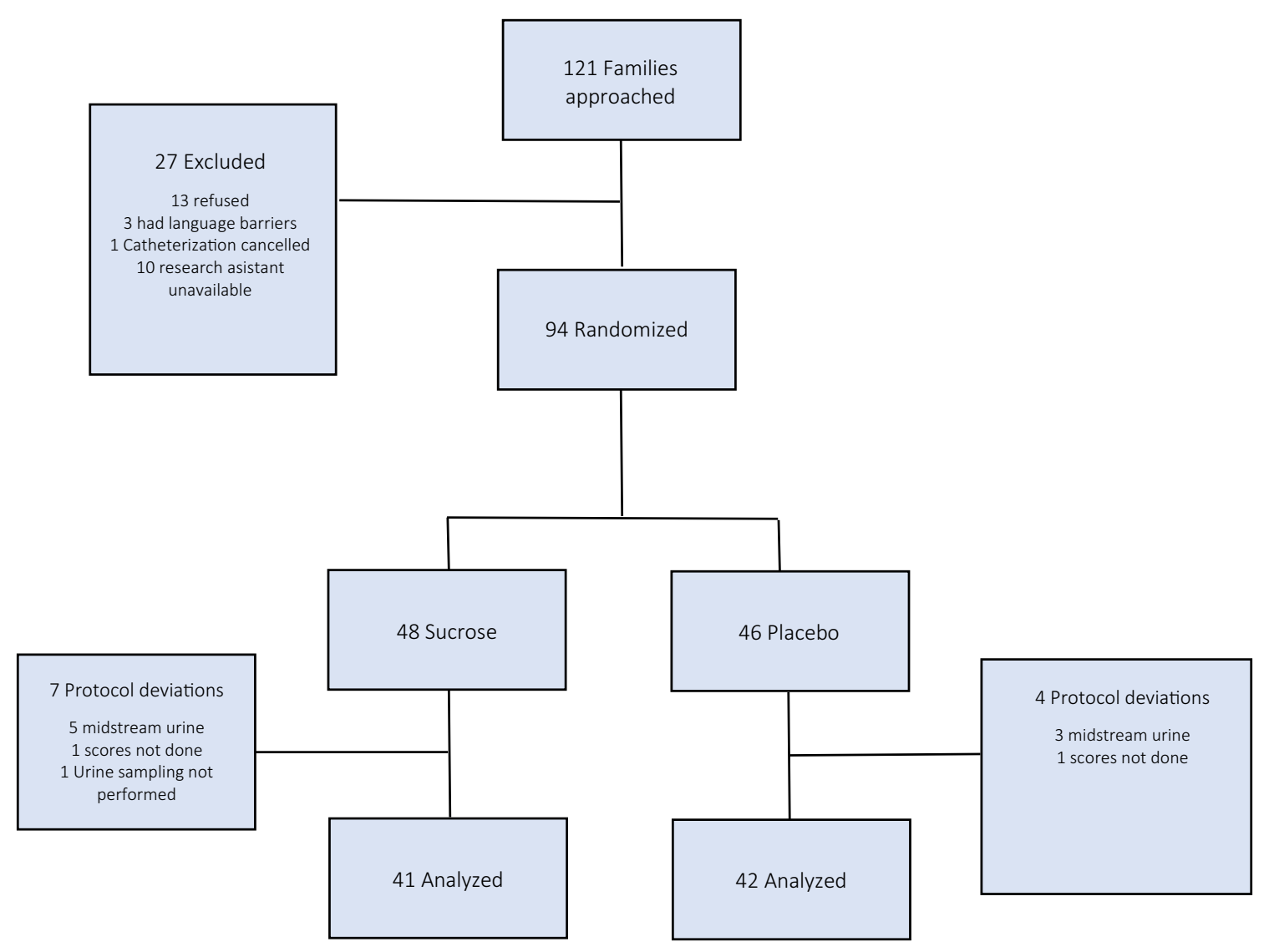

Fig. 1 Study flow 


\section{Intervention}

Families were approached by the research assistant and informed consent was obtained. Following enrollment, patients were randomly assigned to receive one of two oral solutions before bladder catheterization: a $2 \mathrm{ml}$ dose of a sucrose $88 \%$ solution (Syrup B.P.) or a $2 \mathrm{ml}$ dose of a placebo solution (consistency and color matched placebo), in identical packagings. Two syringes were available in case the patient needed a second dose. The bladder catheterization was performed by the treating nurse as per the ED's previously established standardized procedure. Randomization was generated at the local pharmacy by a computer program in blocks of four and the randomization allotment was only known by a pharmacist not involved in the care of the children.

There are currently no pain scores validated in infants 1-3 months old. The FLACC has been validated for children aged 2 months to 7 years old $[17,18]$ and the NIPS is used for newborns aged 0 to 1 month of age [19]. Therefore, both scores were used as the best available proxy to capture the study population's pain. Data were recorded at baseline: FLACC score, NIPS score and heart rate. Then, 2 min before the procedure, the oral solution was given to the infant by the research assistant over a period of 15-30 s. Although it is difficult to determine the exact delay that should exist between the administration of sweet solutions and the performance of a painful procedure, a 2-min delay is recommended in the analgesia model [20], and this timeframe has been used in previous studies [11-13]. If the infant vomited within 2 min of administration, the dose was repeated once. Infants were allowed to use pacifiers at parental discretion, and its use was recorded. The ED nurse proceeded to bladder catheterization 2 min after the oral solution was given. If the infant needed more than one painful procedure as part of their work-up, bladder catheterization was performed first. FLACC and a NIPS scores were recorded during the bladder catheterization and then at 1,3 and $5 \mathrm{~min}$ after the procedure. Heart rate was measured by pulse oximetry every minute for $5 \mathrm{~min}$. Crying time was recorded using a timer from the beginning of the cry during the procedure until the infant stopped crying or for a maximum of $5 \mathrm{~min}$. All outcomes were measured by the research assistant. No other painful procedures or further attempts at bladder catheterization were performed during this 5-min observation period.

\section{Outcome measures}

The primary outcome was pain during bladder catheterization as measured by the FLACC [21] scores in the study population (highest FLACC score during catheterization minus baseline FLACC). The secondary outcomes were the differences in NIPS [22] scores during bladder catheterization and the differences in FLACC and NIPS scores at 1,3 and 5 min after bladder catheterization between both groups. Participants' crying times and changes in heart rates (highest measured heart rate during procedure minus baseline heart rate) were recorded. Side effects and adverse events occurring during administration of the solution were recorded.

\section{Analysis}

Data were collected using a demographic and clinical data form, entered into an Excel database (Microsoft Inc., Richmond, WA) and analyzed with SPSS v24 (IBM Inc). The primary study analysis was a Student's $T$ test to compare the mean differences in score variations (at baseline and after the procedure) between the intervention and the placebo groups. An intention-to-treat approach was used including all children who had a urinary catheterization. Secondary analyses were performed for secondary outcomes using a Student's $T$ test for continuous variables and a Pearson Chi square test for categorical variables. The $95 \%$ confidence intervals were measured for every result. Blinding was assessed by comparing the proportion of appropriate guesses by parents, research assistants and nurses using a Chi square test.

\section{Sample size}

There is no consensus in the literature regarding what might represent a clinically significant difference in FLACC scores. However, an ED pain study [23] hypothesized that a 2-point difference in mean FLACC scores could be assumed to represent a clinically significant difference. In an ED study on nebulized lidocaine to reduce pain and distress during nasogastric tube insertion [24], investigators reported having used a standard deviation of 2.5 points, based on an internal validation study [25] of the FLACC score performed in their center. Based on this information, we chose to use a standard deviation of 2.5 points. Thus, using an alpha error of 0.05 and a power of $90 \%$, it was estimated that 33 patients per group were needed to detect a mean difference of 2 points between the two groups. Given a potential drop-out rate of $10 \%, 37$ patients were needed in each group.

\section{Results}

During the study period, a total of 121 families were approached for the study and 27 were excluded (Fig. 1). Ninety-four patients were eligible to participate, and their parents provided written informed consent. Among them, 11 patients were excluded for protocol deviation, either because 
Table 1 Patients' characteristics

\begin{tabular}{|c|c|c|c|}
\hline & Sucrose $N=41$ & Placebo $N=42$ & $P$ value \\
\hline Median age in days (quartiles) & $60(46,74)$ & $55(43,79)$ & 0.47 \\
\hline $\begin{array}{l}\text { Median gestational age in } \\
\text { weeks (quartiles) }\end{array}$ & $39(38,40)$ & $40(39,41)$ & 0.70 \\
\hline Female $n(\%)$ & $20(49)$ & $10(24)$ & 0.02 \\
\hline $\begin{array}{l}\text { Previous painful procedure } \\
\mathrm{n}(\%)\end{array}$ & $17(41)$ & $19(45)$ & 0.73 \\
\hline $\begin{array}{l}\text { Analgesia in previous } 4 \mathrm{~h} n \\
(\%)\end{array}$ & $19(46)$ & $17(41)$ & 0.59 \\
\hline $\begin{array}{l}\text { Pacifier used during interven- } \\
\text { tion } n(\%)\end{array}$ & $11(27)$ & $11(26)$ & 0.83 \\
\hline First pass success (\%) & $31(76)$ & $38(90)$ & 0.07 \\
\hline Presence of fever at triage & $31(76)$ & $34(81)$ & 0.56 \\
\hline \multicolumn{4}{|l|}{ Catheter size } \\
\hline $6 \mathrm{Fr}$ & $15(37)$ & $23(55)$ & 0.08 \\
\hline $8 \mathrm{Fr}$ & $26(63)$ & $18(45)$ & \\
\hline $\begin{array}{l}\text { Median baseline heart rate } \\
\text { (quartiles) }\end{array}$ & $160(148,172)$ & $152(140,167)$ & 0.63 \\
\hline
\end{tabular}

Table 2 Outcomes (compared to baseline)

\begin{tabular}{lllll}
\hline & Sucrose $N=41$ & Placebo $N=42$ & Difference $(95 \% \mathrm{CI})$ & $P$ value \\
\hline $\begin{array}{l}\text { FLACC difference at } \\
\text { catheterization }\end{array}$ & 5.3 & 6.4 & $-0.9(-2.7-0.8)$ & 0.12 \\
$\begin{array}{l}\text { NIPS difference at cath- } \\
\text { eterization }\end{array}$ & 4.0 & 4.7 & $-0.7(-2.1-0.7)$ & 0.06 \\
$\begin{array}{l}\text { Variation in heart rate at } \\
\text { catheterization (bpm) }\end{array}$ & 24 & 27 & $-3(-14-7)$ & 0.68 \\
$\begin{array}{l}\text { Crying time (sec) } \\
\text { Side effects (\%) }\end{array}$ & 97 & 110 & $-12(-56-31)$ & 0.31 \\
\hline
\end{tabular}

Table 3 Outcomes at different times

\begin{tabular}{lllll}
\hline & Sucrose $N=41$ & Placebo $N=42$ & Difference $(95 \% \mathrm{CI})$ & $P$ value \\
\hline FLACC difference at $1 \mathrm{~min}$ & 3.0 & 2.3 & $0.6(-1.2-2.4)$ & 0.27 \\
FLACC difference at $3 \mathrm{~min}$ & 0.3 & 1.4 & $-1.1(-2.5-0.3)$ & 0.34 \\
FLACC difference at $5 \mathrm{~min}$ & 0.5 & -0.1 & $0.6(-0.7-1.8)$ & 0.73 \\
NIPS difference at $1 \mathrm{~min}$ & 2.3 & 2.0 & $0.3(-1.1-1.7)$ & 0.13 \\
NIPS difference at $3 \mathrm{~min}$ & 0.2 & 1.0 & $-0.9(-2.2-0.4)$ & 0.21 \\
NIPS difference at $5 \mathrm{~min}$ & -0.4 & 0.0 & $-0.4(-1.7-0.8)$ & 0.80 \\
Variation in heart rate at $1 \mathrm{~min}(\mathrm{bpm})$ & 21 & 17 & $4(-10-19)$ & 0.19 \\
Variation in heart rate at 3 $\min (\mathrm{bpm})$ & -4.6 & 4.5 & $-9(-23$ to 5) & 0.18 \\
Variation in heart rate at 5 $\mathrm{min}(\mathrm{bpm})$ & -2 & -1 & $-0.2(-9-8)$ & 0.31 \\
\hline
\end{tabular}

no bladder catheterization was performed $(n=9)$ or because the scores were not measured $(n=2)$ (Fig. 1). Therefore, we included 41 patients in the sucrose group and 42 patients in the placebo group for the primary analysis. Among all the included patients, bladder catheterization was successful at the first attempt for 69 of them (83\% first attempt success rate). To perform the catheterizations, size 8 French or size 6 French catheters were used $54 \%$ and $46 \%$ of the time, respectively.

Patients' baseline characteristics were similar in both groups, although there were more female participants in the sweet solution group (Table 1). Median age was 58 days, $40 \%$ of the participants received acetaminophen in the four hours preceding the procedure and $25 \%$ used a pacifier during the procedure. The average delay between administration 
Table 4 Number of participants who appropriately guessed of the randomisation group

\begin{tabular}{llll}
\hline & All children & Sucrose & Placebo \\
\hline Research assistants $(\% ; 95 \% \mathrm{CI})$ & $42 / 77(55 ; 43-65)$ & $26 / 38(68 ; 52-81)$ & $16 / 39(41 ; 27-57)$ \\
Nurses $(\% ; 95 \% \mathrm{CI})$ & $41 / 77(53 ; 42-63)$ & $26 / 38(68 ; 52-81)$ & $15 / 39(39 ; 25-54)$ \\
Parents $(\% ; 95 \% \mathrm{CI})$ & $39 / 70(56 ; 44-67)$ & $22 / 34(65 ; 48-79)$ & $17 / 36(47 ; 32-63)$ \\
\hline
\end{tabular}

of the oral solution and beginning of bladder catheterization was $2 \min 54 \mathrm{~s}$.

The difference in FLACC scores between groups during bladder catheterization was not statistically significant (Table 2). The NIPS scores, variation in heart rates and overall crying times were also similar in the sucrose and placebo groups during bladder catheterization. (Table 2). There were no significant side effects (Table 2). One patient vomited the first dose and was administered a second dose of sucrose $1 \mathrm{~min}$ after the first. Two patients coughed after ingesting the sucrose.

There was no difference in FLACC scores and NIPS scores measured at 1, 3 and 5 min post procedure (Table 3 ).

Between 56 and $63 \%$ of the research assistants, nurses and parents accurately identified what oral solution (placebo or sucrose) the child was randomized to receive (Table 4). This was similar for both interventions.

\section{Discussion}

\section{Interpretation of findings}

In children aged 1-3 months old, this randomized placebocontrolled study found no statistically significant difference in pain scores, heart rates or crying times between children who received an $88 \%$ oral sucrose solution 2 min before the procedure and those who received placebo.

\section{Comparison to previous studies}

Bladder catheterization is one of the most common painful procedures performed in the ED [26, 27] in infants 1-3 months old and methods to treat this procedural pain would be highly beneficial to children. Sucrose has proven effective to treat procedural pain in infants less than 1 month old, but has demonstrated controversial results in secondary analyses involving infants 1-3 months, or in studies of other painful procedures $[7,11,13]$. The present study was therefore conducted to examine the effect of an oral sucrose solution in this specific age group, finding no difference between sucrose and placebo.

Previous studies conducted by our group examined the effect of an oral sweet solution in infants during intravenous cannulation and venipuncture $[12,15]$. These studies did not find a statistically significant improvement in pain scores with the use of an oral sweet solution, but crying time trended towards statistical significance as a secondary outcome. One of the limitations we identified in our previous studies concerned delayed timing of the measurement of pain scales (scores were measured for the first time 1 min after the procedure had begun). Therefore, in our present study, pain measurement was recorded from the beginning of the procedure, when it was believed the pain experience may be maximal. Nonetheless, no differences in pain scores at the beginning of bladder catheterization were observed.

The pharmacological effect of sucrose in infants remains uncertain and controversial. Animal studies have demonstrated that sweet solutions may provide analgesia by influencing central endorphin responses to pain stimuli [28]. A study published in 2003 failed to demonstrate elevation of plasmatic b-endorphin in preterm infants after administration of sucrose [29]. Some experts believe that sweet solutions might decrease pain scores through its provision of nonnutritive sucking and distraction and not through a direct analgesic effect on endorphins [30]. Indeed, in a study of Ramenghi and al, sucrose demonstrated beneficial effects when given orally, but not when administered via a nasogastric tube [31]. If the benefits of sucrose are based on its distraction and nonnutritive sucking effects, then its effects may be more pronounced if the oral solutions were administered during the painful procedure. Future studies should be conducted to evaluate this possibility.

\section{Strengths and limitations}

To our knowledge, this is the first study to examine the effect of an oral sweet solution on pain during bladder catheterization in infants 1-3 months of age. Although the use of sweet solutions has been demonstrated highly efficacious during many painful procedures $[7,32,33]$ in the newborn period (0-1 months), its effect in older infants is still controversial, with several studies demonstrating trends towards improvements in pain scores without achieving statistical significance [11-15].

One of the main limitations of this study is that there are currently no pain scores validated for the study population. Both scores were used to allow for the best assessment of the study population's pain using the available validated tools. Also, these pain scores are designed for use on a freely moving patient. However, during bladder catheterization, 
patients' legs and arms are restrained, making it harder to assess limb movement, one of the key elements in both the FLACC and the NIPS scores. Our study was conducted in a single, university-affiliated ED, and our results may not apply to other settings. Our sample size was small and provided large confidence intervals for the differences. However, we found no statistical impact of the intervention for all outcomes. Finally, this study's data were collected in 2014 and although this may seem to limit its applicability several years later, an updated literature review confirmed that new findings on this topic have yet to demonstrate findings that would change current practices in bladder catheterizations in infants or its pain treatment.

\section{Clinical and research implications}

There were no significant side effects to using a sweet solution in infants 1-3 months old, but its use may not be sufficient to treat infants' pain in this age category. Although this study did not demonstrate statistical benefits, future studies should examine the effect of timing of sweet solution administration on procedural pain.

\section{Conclusion}

In conclusion, for infants aged 1-3 months old undergoing bladder catheterization in the ED, administration of an oral sweet solution 2 min before the procedure did not statistically decrease pain scores as measured by the FLACC and NIPS scales. Participants' heart rate variations and crying time were also not significantly decreased when sucrose was provided instead of the placebo.

Supplementary Information The online version contains supplementary material available at https://doi.org/10.1007/s43678-021-00130-x.

\section{Declarations}

Conflict of Interest The authors declare that they have no conflict of interest.

\section{References}

1. Weisman SJ, Bernstein B, Schechter NL. Consequences of inadequate analgesia during painful procedures in children. Arch Pediatr Adolesc Med. 1998;152(2):147-9.

2. Trottier E, Doré-Bergeron MJ, Chauvin-Kimoff L, Baerg K, Ali S. Managing pain and distress in children undergoing brief diagnostic and therapeutic procedures. Paediatr Child Health. 2019;24(8):509-21.

3. Labrosse M, Levy A, Autmizguine J, Gravel J. Evaluation of a new strategy for clean-catch urine in infants. Pediatrics. 2016;138(3):pii.e20160573.
4. Robinson JL, Finlay JC, Lang ME, Bortolussi R. Urinary tract infections in infants and children: diagnosis and management. Paediatr Child Health. 2014;19(6):315-25.

5. Roberts KB. Urinary tract infection: clinical practice guideline for the diagnosis and management of the initial UTI in febrile infants and children 2-24 months. Pediatrics. 2011;128(3):595-610.

6. Poonai N, Li J, Langford C, Lepore N, Taddio A, Gerges S, et al. Intraurethral lidocaine for urethral catheterization in children: a randomized controlled trial. Pediatrics. 2015;136(4):879-86.

7. Harrison D, Bueno M, Yamada J, Adams-Webber T, Stevens B. Analgesic effects of sweet-tasting solutions for infants: current state of equipoise. Pediatrics. 2010;126(5):894-902.

8. Hatfield LA, Gusic ME, Dyer AM, Polomano RC. Analgesic properties of oral sucrose during routine immunizations at 2 and 4 months of age. Pediatrics. 2008;121(2):e327-34.

9. Thyr M, Sundholm A, Teeland L, Rahm VA. Oral glucose as an analgesic to reduce infant distress following immunization at the age of 3, 5 and 12 months. Acta Paediatr. 2007;96(2):233-6.

10. Dilli D, Küçük IG, Dallar Y. Interventions to reduce pain during vaccination in infancy. J Pediatr. 2009;154(3):385-90.

11. Curtis SJ, Jou H, Ali S, Vandermeer B, Klassen T. A randomized controlled trial of sucrose and/or pacifier as analgesia for infants receiving venipuncture in a pediatric emergency department. BMC Pediatr. 2007;18(7):27.

12. Gouin S, Gaucher N, Lebel D, Desjardins MP. A randomized double-blind trial comparing the effect on pain of an oral sucrose solution vs placebo in children 1-3 months old undergoing simple venipuncture. J Emerg Med. 2018;54(1):33-9.

13. Rogers AJ, Greenwald MH, Deguzman MA, Kelley ME, Simon $\mathrm{H}$. A randomized, controlled trial of sucrose analgesia in infants younger than 90 days of age who require bladder catheterization in the pediatric emergency department. Acad Emerg Med. 2006;13(6):617-22.

14. London K, Watson H, Kwok S, Nanan R, Liu A. Oral sucrose for analgesia in children aged between 3 months and 3 years undergoing transurethral bladder catheterisation: a randomised, doubleblinded, clinical trial. J Paediatr Child Health. 2020;56(2):207-14.

15. Desjardins MP, Gaucher N, Curtis S, LeMay S, Lebel D, Gouin S. A randomized controlled trial evaluating the efficacy of oral sucrose in infants 1-3 months old needing intravenous cannulation. Acad Emerg Med. 2016;23(9):1048-53.

16. Gao H, Gao H, Xu G, Li M, Du S, Li F, Zhang H, Wang D. Efficacy and safety of repeated oral sucrose for repeated procedural pain in neonates: a systematic review. Int J Nurs Stud. 2016;62:118-25.

17. McGrath PJ, Walco GA, Turk DC, Dworkin RH, Brown MT, Davidson K, et al. Core outcome domains and measures for pediatric acute and chronic/recurrent pain clinical trials: PedIMMPACT recommendations. J Pain. 2008;9(9):771-83.

18. Merkel SI, Voepel-Lewis T, Shayevitz JR, Malviya S. The FLACC: a behavioral scale for scoring post-operative pain in young children. Pediatr Nurs. 1997;23(3):293-7.

19. Uyan ZS, Bilgen H, Topuzoglu A, Akman I, Ozek E. Comparison of three neonatal pain scales during minor painful procedures. J Matern Fetal Neonatal Med. 2008;21(5):305-8.

20. Blass EM, Shah A. Pain-reducing properties of sucrose in human newborns. Chem Senses. 1995;20(1):29-35.

21. Merkel SI, Voepel-Lewis T, Shayevitz JR, Malvina S. The FLACC: a behavioral scale for scoring postoperative pain in young children. Pediatr Nurs. 1997;23(3):293-7.

22. Lawrence J, Alcock D, McGrath P, Kay J, MacMurray SB, Dulberg $\mathrm{C}$. The development of a tool to assess neonatal pain. Neonatal Netw. 1993;12(6):59-66.

23. Vaughan M, Paton EA, Bush A, Pershad J. Does lidocaine gel alleviate the pain of bladder catheterization in young children? A randomized, controlled trial. Pediatrics. 2005;116(4):917-20. 
24. Babl FE, Goldfinch C, Mandrawa C, Crellin D, O'Sullivan R, Donath $\mathrm{S}$. Does nebulized lidocaine reduce the pain and distress of nasogastric tube insertion in young children? A randomized, double-blind, placebo-controlled trial. Pediatrics. 2009;123(6):1548-55.

25. Sullivan T, Crellin D, Babl F, O'Sullivan R, Hutchinson A. Measuring pain and distress during procedures in preverbal and early verbal children in the emergency department [abstract]. J Peadiatr Child Health. 2007;43:A12.

26. McCaig LF, Burt CW. National hospital ambulatory medical care survey: 2003 emergency department summary. Adv Data Vital Health Stat [Internet]. Available from: http://www.cdc.gov/nchs/ data/ad/ad358.pdf. Accessed 26 May 2005

27. MacLean S, Obispo J, Young KD. The gap between pediatric emergency department procedural pain management treatments available and actual practice. Pediatr Emerg Care. 2007;23(2):87-93.
28. Ganong FW. Review of medical physiology. Appleton and Lange; 1995.

29. Taddio A, Shah V, Shah P, Katz J. $\beta$-Endorphin concentration after administration of sucrose in preterm Infants. Arch Pediatr Adolesc Med. 2003;157(11):1071-4.

30. Blass EM, Ciaramitaro V. A new look at some old mechanisms in human newborns: taste and tactile determinants of state, affect and action. Monogr Soc Res Child Dev. 1994;59(1):1-81.

31. Ramenghi LA, Evans DJ, Levene MI. "Sucrose analgesia": absorptive mechanism or taste perception? Arch Dis Child Fetal Neonatal Ed. 1999;80(2):F146-7.

32. Acharya AB, Annamali S, Taub NA, Field D. Oral sucrose analgesia for preterm infant venipuncture. Arch Dis Child Fetal Neonatal Ed. 2004;89(1):F17-8.

33. Herschel M, Khoshnood B, Ellman C, Maydew N, Mittendorf R. Neonatal circumcision. Randomized trial of a sucrose pacifier for pain control. Arch Pediatr Adolesc Med. 1998;152(5):279-84. 